\title{
Impervious surface and local abiotic conditions influence arthropod communities within urban greenspaces
}

\author{
Garrett M Maher ${ }^{1}$, Graham Johnson ${ }^{1}$, Justin D Burdine ${ }^{\text {Corresp. } 1}$ \\ ${ }^{1}$ Division of Science and Kinesiology, Cornerstone University, Grand Rapids, Michigan, United States of America \\ Corresponding Author: Justin D Burdine \\ Email address: justin.burdine@cornerstone.edu
}

The abundance of arthropods is declining globally, and human-modification of natural habitat is a primary driver of these declines. Arthropod declines are concerning because arthropods mediate critical ecosystem functions, and sustained declines may lead to cascading trophic effects. There is growing evidence that properly managed urban environments can provide refugium to arthropods, but few cities have examined arthropods within urban greenspaces to evaluate their management efforts. In this study, we surveyed arthropod communities within a medium-sized, growing city. We investigated arthropod communities (abundance, richness, diversity, community composition) within 16 urban greenspaces across metropolitan Grand Rapids, Michigan (USA). We focused our efforts on urban gardens and pocket prairies, and measured environmental variables at each site. We collected 5,468 individual arthropods that spanned 14 taxonomic orders and 66 morphospecies. The results showed that community composition was influenced by impervious surface, white flower abundance, and humidity. Total arthropod abundance and diversity were positively associated with humidity. For specific orders, Hymenoptera (bees, ants, wasps) abundance was negatively associated with temperature, and positively associated with site perimeter-area ratio. Hemiptera (true bugs) were negatively associated with impervious surface and positively associated with humidity. These findings show that impervious surfaces impact arthropod communities, but many of the observed changes were driven by local abiotic conditions like temperature and humidity. This suggests that management decisions within urban greenspaces are important in determining the structure of arthropod communities. Future studies on arthropods in cities should determine whether manipulating the abiotic conditions of urban greenspaces influences the composition of arthropod communities. These results should inform city planners and homeowners of the need to properly manage urban greenspaces in cities to maintain diverse arthropod assemblages. 
1 Manuscript Title: Impervious surface and local abiotic conditions influence arthropod

2 communities within urban greenspaces

3

4 Garrett M Maher ${ }^{1}$, Graham Johnson ${ }^{1}$, Justin D Burdine ${ }^{1}$

5

$6 \quad{ }^{1}$ Division of Science and Kinesiology, Cornerstone University, Grand Rapids, Michigan, USA 7

8 Corresponding Author:

9 Justin D Burdine

1001 E. Beltline Ave NW, Grand Rapids, Michigan, 49418, USA

11 Email Address: justin.burdine@cornerstone.edu

\section{Abstract}

The abundance of arthropods is declining globally, and human-modification of natural

habitat is a primary driver of these losses. Arthropod declines are concerning because arthropods mediate critical ecosystem functions, and sustained reductions may lead to cascading trophic

17 effects. There is growing evidence that properly managed urban environments can provide

18 refugium to arthropods, but few studies in cities have examined arthropods within urban greenspaces to evaluate their management efforts. In this study, we surveyed arthropod communities (abundance, richness, diversity, community composition) within 16 urban 21 greenspaces across metropolitan Grand Rapids, Michigan (USA). We focused our efforts on 22 urban gardens and pocket prairies, and measured environmental variables (percent impervious 23 surface, site perimeter-area ratio, temperature, humidity, total flowers, white flowers, purple 
24 flowers) at each site. We collected 5,468 individual arthropods that spanned 14 taxonomic orders 25 and 66 morphospecies. The results showed that community composition was influenced by 26 impervious surface, white flower abundance, and humidity. Total arthropod abundance and 27 diversity were positively associated with humidity. For specific orders, Hymenoptera (bees, ants, wasps) abundance was negatively associated with temperature, and positively associated with

site perimeter-area ratio. Hemiptera (true bugs) were negatively associated with impervious surface and positively associated with humidity. These findings show that impervious surfaces impact arthropod communities, but many of the observed changes were driven by local abiotic conditions like temperature and humidity. This suggests that management decisions within urban greenspaces are important in determining the structure of arthropod communities. Future studies on arthropods in cities should determine whether manipulating the abiotic conditions of urban greenspaces influences the composition of arthropod communities. These results should inform city planners and homeowners of the need to properly manage urban greenspaces in cities to maintain diverse arthropod assemblages.

\section{Introduction}

Urban environments are understood to be regions that have been altered to accommodate a growing human population, and are characterized by high densities of people and impervious surfaces such as roads, buildings, sidewalks, and parking lots. Over half the global human population resides in urban environments, and $82 \%$ of the United States' population is classified as urban (United Nations 2018). The global human population continues to rise, and the United Nations estimates that an additional 2.5 billion people will be urban dwellers by 2050 (2018). This places pressure on urban regions to maintain quality habitat for human well-being, and to 
47 sustain the delivery of critical ecosystem services for urban residents. Continued urban

48 expansion encroaches into the peri-urban landscape (Smidt et al. 2018), and leads to

49 fragmentation and natural habitat loss. Impervious surfaces replace greenspaces as urban centers

50 expand outward into agricultural and natural lands (Smidt et al. 2018), and can alter the abiotic

51 conditions of cities, increasing land surface temperature (Gaffin et al. 2008) and reducing water

52 availability (Jiang et al. 2015). Therefore, it is important to understand how continued

53 urbanization impacts the biotic communities that perform the ecosystem functions that are

54 essential for human well-being in cities.

55 Many studies have documented the biotic homogenization or convergence of cities

56 (McKinney 2006, Wittig and Becker 2010, Groffman et al. 2014, Lemoine-Rodríguez et al.

57 2020), and impervious surfaces play a significant role in establishing similar patterns of

58 fragmentation and ecosystem structure that underlie this homogenization (Groffman et al. 2017).

59 An additional component to this homogenization are the plant communities that become

60 established within urban greenspaces. Non-native plants are often drivers of homogenization

61 (McKinney 2004, Cubino et al. 2019) because they establish similar habitats that attract the same

62 types of arthropods in cities (Knop 2016). Although biotic homogenization may increase local

63 species richness, diversity at the regional or global scale tends to decline (Dar and Reshi 2014).

64 This leads to functional homogenization as native, specialist species are replaced by non-native

65 generalists that are unable to perform the same ecosystem functions (Merckx and Dyck 2019).

66 However, there is growing evidence that cities can harbor diverse plant communities with

67 arthropods that counter this homogenization effect (Pardee and Philpott 2014, Hall et al. 2017,

68 Joimel et al. 2019). 
Arthropods are the most diverse phylum of animals on Earth, and they maintain

70

71

72 73

74 75

ecosystem functions as pollinators, decomposers, herbivores, and predators, amongst others.

Within cities, arthropod communities often experience dissimilar responses. The overall abundance and diversity of arthropods tends to decline as impervious surfaces increase (Lagucki et al. 2017, Miles et al. 2019, Fenoglio et al. 2020). However, arthropod responses to urbanization are also driven by the abiotic and biotic conditions within urban greenspaces. For instance, urbanization can influence temperature and water availability due to urban heat island effects (Gaffin et al. 2008), and altered water drainage and infiltration patterns (Shuster et al. 2005). Research within cities has shown that temperature is often a better predictor than impervious surface at explaining shifts in the diversity of specific arthropod groups like true flies (McGlynn et al. 2019). And studies have found that increased irrigation in urban regions may have positive impacts on specific arthropods like aphids (Andrade et al. 2017). In terms of the biotic conditions, increasing the availability of vegetation (Turrini and Knop 2015), and principally flowers (Mody et al. 2020), can lead to increased arthropod abundance. The types of flowers present also help explain their positive impacts on bees (Pardee and Philpott 2014, Burdine and McCluney 2019b) and natural enemies (Dale et al. 2020). This study focused on arthropod communities in Grand Rapids, Michigan, USA. Urban land in Grand Rapids increased by 204\% between 1992 to 2011, and urban land is projected to increase an additional $35 \%$ by 2050 (Smidt et al. 2018). The city contains many urban gardens and pocket prairies that harbor native plant species, and may be important habitats for arthropods as studies in nearby cities have shown (Pardee and Philpott 2014). Furthermore, these habitats provide valuable ecosystem services, such as food production and recreation, and have been identified as important public greenspaces for urban development (Turo and Gardiner 2019). 
92 Grand Rapids is one of the fastest growing cities in the Midwest (Sharf 2018), and is in a unique

93 position because the urban center is surrounded by natural land cover (Smidt et al. 2018). Thus,

94 understanding the structure of arthropod communities can provide context for similar studies in

95 the future as urban expansion continues into these natural habitats.

The primary objective of this study was to survey arthropod communities (abundance,

97 richness, diversity, composition) along an urbanization gradient (impervious surface) within a

98 network of urban gardens and pocket prairies. We measured the environmental conditions

99 (percent impervious surface, site perimeter-area ratio, temperature, humidity, total flowers, white

100 flowers, purple flowers) within each site to better understand drivers of change within arthropod

101 communities, and to identify interventions that land managers can implement to support diverse

102 arthropod assemblages. We expected impervious surface at the landscape scale to be the

103 dominant driver in community structure, and that overall arthropod abundance would decline

104 near the urban center (high impervious surface). For biotic conditions, we expected floral

105 resource availability to be the dominant factor in explaining changes in arthropod richness and

106 diversity.

107

108 Materials and Methods

109 Site Selection

110 Arthropods were sampled from 8 urban gardens and 8 pocket prairies across metropolitan

111 Grand Rapids, Michigan, USA (see Figure 1). Urban gardens were predominately compromised

112 of edible plants, but often contained non-edible wildflowers. The urban garden sites were located

113 on non-residential properties, and functioned as community garden spaces for groups of

114 individuals to manage. Pocket prairies were defined as habitats that have undergone a restoration 
115 process through the intentional planting of native prairie plant species. Sites were compiled by

116 first establishing a list of known pocket prairies and urban gardens within a $25 \mathrm{~km}$ radius of

117 Grand Rapids City Hall as a proxy of the city center. Then, permissions were request for each

118 site to visit and collect specimens during the summer of 2020. We secured permissions from 16

119 collection sites that were spatially separated by a minimum distance of $750 \mathrm{~m}$ between each site

120 to maintain the spatial independence of each research site and reduce pseudoreplication. Sites

121 were managed by the City of Grand Rapids, City of Hudsonville, Township of Ada, Township of

122 Gaines, Creston Neighborhood Association, Blandford Nature Center, New City Neighbors,

123 Urban Roots, Dominican Sisters of Grand Rapids, Fairway Christian Reformed Church,

124 Rosewood Church, Calvin University, and Cornerstone University.

Sampling Methods

127 Each site was sampled once per month (June, July) on sunny days with temperatures 128 above $70^{\circ} \mathrm{F}\left(21.1^{\circ} \mathrm{C}\right)$. Sampling occurred in the morning $(8 \mathrm{am}-10 \mathrm{am})$ and afternoon $(3 \mathrm{pm}-5$ $129 \mathrm{pm}$ ) on the same day. During each sampling event, multiple measurements were taken near the 130 center of each site in a region that contained visible vegetation representative of the habitat 131 (urban garden, pocket prairie). The temperature and relative humidity were recorded using a 132 digital psychrometer (Model \# CECOMINID048683). From the site center, a $15 \mathrm{~m}$ transect was 133 marked and the total number of individual flowering plants and their colors (white, yellow, 134 purple) were recorded within $1 \mathrm{~m}$ of the transect, as others have done (Pardee and Philpott 2014, 135 Otoshi et al. 2015, Burdine and McCluney 2019c). We considered inflorescences to be a single 136 flower. To sample the arthropods, 12 large $350 \mathrm{~mL}$ bowls (4 blue, 4 yellow, 4 white) and 12 137 small $175 \mathrm{~mL}$ bowls (4 blue, 4 yellow, 4 white) were placed along the transect. Both small and 
138 large sampling bowls were used to capture arthropods of varying sizes. Each bowl contained a

139 soap (Dawn) and water mixture to prevent specimens from escaping the bowls. Bowls were set

140 out in the morning and retrieved in the afternoon on the same day. Upon collection, samples

141 were placed into plastic collection containers filled with $70 \%$ ethanol for later identification. The

142 collection containers were then labeled and stored at Cornerstone University (Grand Rapids,

143 Michigan, USA).

144 All arthropods sampled were identified to morphospecies (S1). Arthropod abundance was

145 calculated as the total number of arthropods measured at each site, and morphospecies richness

146 was calculated as the total number of morphospecies present at each site. For the diversity

147 metric, we calculated the Shannon diversity index. We combined arthropod samples from June

148 and July together, and environmental variables between both months were averaged. For

149 temperature and humidity values, we average the measurements taken during morning sampling

150 events.

151

152 Landscape Characteristics

153 The percent of impervious surface for each site was calculated using the 2016 National

154 Land Cover Dataset (NLCD) Percent Developed Imperviousness layer (Homer et al. 2020) in

155 ArcGIS v 10.7. The impervious surface value at each site was calculated by placing a $500 \mathrm{~m}$

156 radius buffer around each site, and averaging the impervious surface grid cells from the NLCD

157 dataset. The area, perimeter, and perimeter-area ratio of each site were measured using Google

158 Earth Pro v 7.3.3.7786.

159

160 Statistical Methods 
All statistical analyses were completed using the statistical program $\mathrm{R}$ version 3.6.2 ( $\mathrm{R}$

162 Core Team 2019). Within this program, we used the "vegan" package to conduct a permutation

163 analysis of variance test (PERMANOVA) on arthropod community composition. Non-metric

164 multidimensional scaling (metaMDS) was utilized to display significant associations between

165 arthropod community composition and environmental factors. The "vegan" package was also

166 used to calculate the Shannon diversity index. The correlation function (cor) was used to check

167 collinearity between environmental variables (S2). Variables with a correlation coefficient above

$168 \mathrm{r}= \pm 0.7$ were considered correlated, and when this occurred one of the variables was removed

169 from the statistical analyses.

170 Generalized linear models $(G L M s)$ were used to compare environmental variables

171 (percent impervious surface, site perimeter-area ratio, temperature, humidity, total flowers, white

172 flowers, purple flowers) against response variables (abundance, diversity, morphospecies

173 richness). For arthropod orders with more than 500 individuals sampled, we used the abundance

174 and morphospecies richness of the order as response variables. We established a list of candidate

175 models that examined each environmental variable separately (S3). From this list of candidate

176 models, the model for each response variable with the lowest AICc value was selected. Models

177 within 2 AICc units were considered equivalent, and these models were combined to determine

178 whether an additive or interactive model was a better fit (S4). When the most parsimonious

179 model for a response metric was within 2 AICc units of the null model, we reported the results of

180 the null (Table 2). In addition, we used the site type (urban garden, pocket prairie) as an additive

181 variable to evaluate the sites utilized in our study. We chose this process to simplify model

182 selection because additive and interactive models are problematic with model averaging

183 approaches (Cade 2015, Harrison et al. 2018). We tested for overdispersion in all models, and 
184 made adjustments by altering family distributions when overdispersion was an issue. The 185 distribution families used after testing for overdispersion were negative binomial (total arthropod 186 abundance, Hymenoptera abundance, Hemiptera abundance, Diptera abundance), Gaussian 187 (diversity), and Poisson (morphospecies richness, Diptera richness, Hemiptera richness, 188 Hymenoptera richness). Assumptions of normality and equal variance were assessed by residual 189 plots, and data transformation were performed when necessary.

190

\section{Results}

192 Summary Statistics

193

A total of 5,468 individuals were collected that represented 14 different taxonomic 194 orders of arthropods and 66 morphospecies. The majority of arthropods sampled ( $88 \%)$ were 195 classified into three orders: Diptera (2,604 individuals), Hemiptera (1,156 individuals). and Hymenoptera (1,026 individuals). The orders Araneae (128 individuals), Coleoptera (330 197 individuals), and Orthoptera (145 individuals) were less abundant, but were represented by at least 100 individuals. The remaining 8 orders contained a combined abundance of 79 individuals $199(\sim 1 \%)$. Looking at the response variables at the site level, we report the ranges in total arthropod abundance (126 - 586 individuals), diversity $(2.10-2.73)$, and morphospecies richness $(23-39$ 201 morphospecies).

202 The environmental variables we measured also displayed a broad range of values that 203 reflect the conditions of each site. We report the ranges of total flower abundance $(23-188$ 204 flowers $)$, purple flower abundance (0.5 - 50.5 flowers $)$, white flower abundance (1.5 - 70 205 flowers), humidity $(37.7 \%-65.1 \%)$, temperature $\left(21.8^{\circ} \mathrm{C}-32.1^{\circ} \mathrm{C}\right)$, impervious surface $(21.9 \%$ $206-62.3 \%)$, and perimeter-area ratio $(1.1-5.1)$. 
208

209

210

211

212

213

214

215

216

217

218

219

220

221

222

223

224

225

226

227

161.21, $\mathrm{R}^{2}=0.57$, Figures $3 \mathrm{~A}$ and $\left.3 \mathrm{~B}\right)$. Hymenoptera abundance was negatively associated

229 with temperature $\left(\mathrm{AICc}=145.32, \mathrm{R}^{2}=0.29\right.$, Figure $\left.4 \mathrm{C}\right)$, and positively associated with 
230 perimeter-area ratio $\left(\mathrm{AICc}=147.25, \mathrm{R}^{2}=0.2\right.$, Figure $\left.4 \mathrm{D}\right)$. Hymenoptera abundance was also 231 explained by an additive model of temperature and perimeter-area ratio $\left(\mathrm{AICc}=147.32, \mathrm{R}^{2}=\right.$ 232 0.36). The remaining response metrics (Diptera abundance, Hymenoptera richness, Hemiptera 233 richness, Diptera richness) were not statistically different from the null models (Table 2).

234

235 Discussion

236 Our results reveal important patterns in how arthropod communities are impacted by 237 urbanization. Both abiotic (impervious surface, humidity) and biotic (white flower abundance) 238 conditions influenced overall arthropod community structure, and the composition of 239 morphospecies present. In addition, response variables (abundance, richness, diversity) were also 240 associated with abiotic (impervious surface, temperature, humidity) and biotic (purple flower 241 abundance, perimeter-area ratio) site conditions. This suggests that the stability of arthropod 242 communities and their associated ecosystem services may require multiple intervention points by 243 land managers. The importance of habitat structure (McIntyre et al. 2001, Whitehouse 2004, 244 Braaker et al. 2014), water availability (Lagucki et al. 2017, McCluney et al. 2018, Miles et al. 245 2019), and floral resources (Bennett and Gratton 2012, Burdine and McCluney 2019c, Wilson 246 and Jamieson 2019) on arthropods in cities is well documented in the literature. However, the 247 impact of abiotic conditions on Hymenoptera and Hemiptera shows that the impacts of 248 urbanization on these arthropods may be difficult to address. Similar work on bees 249 (Hymenoptera) in cities reveals that increasing floral resources is unlikely to conserve diverse 250 bee communities due to the strong impacts of urban warming (Hamblin et al. 2018). 

communities. Water availability can influence the behavior (Green et al. 2005) and physiology (McCluney et al. 2017, Burdine and McCluney 2019a) of arthropods, and can limit arthropod populations (Allen et al. 2014, Khaliq et al. 2014, Lagucki et al. 2017). Many arthropods that dwell in soil and plant roots require high moisture levels to prevent desiccation (Bayley and Holmstrup 1999), and we know that impervious surfaces in cities change soil moisture by altering hydrology (Shuster et al. 2005). Since urban gardens and parks often utilize irrigation systems, these could be important inputs for maintaining abundant and diverse arthropod communities. In addition, repurposing vacant land into raingardens could provide multiple ecosystem services by capturing excess storm water runoff (Turo and Gardiner 2019), and providing habitat for arthropods. Others have suggested that shade trees in urban environments may be important in providing moisture for arthropods. McCluney and Sabo (2009) found that crickets increased the consumption of moist leaves to meet their water needs when moisture availability was low. Adding sources of shade and moisture may counteract the negative impacts reduced humidity has on arthropods.

In terms of temperature, many studies have documented the impacts urban warming has on Hymenoptera. Thermal tolerance is often used to explain changes in arthropod community structure (Youngsteadt et al. 2017, Hamblin et al. 2017, Miles et al. 2019), and species-specific responses (Diamond et al. 2017, Burdine and McCluney 2019a) across urbanization gradients.

272 For instance, Hamblin et al. (2018) found sharp declines in bee abundance across an urbanization 273 gradient, and temperature was the dominant variables in explaining these changes. Therefore, it 274 is not surprising that we detected declines in Hymenoptera with temperature. We did identify a 275 positive association between white flower abundance with Lasioglossum (sweat bees), but it is 
276 notable that overall floral resources availability had no influence on Hymenoptera. This suggests

277 that simply planting more flowers may not impact Hymenoptera unless interventions addressing 278 temperature are addressed.

279

280

281

282

283

284

285

286

287

288

289

290

291

292

293

294

295

296

297 298

Site Structure

Impervious surface was a strong driver of arthropod community composition. In particular, we observed declines in Hemiptera (true bugs) with increasing impervious surface. In general, arthropod declines are common in cities (Ahrné et al. 2009, Fenoglio et al. 2020), as impervious surfaces replace natural vegetation cover. However, even at our most urban site (62.3\% impervious surface) there is still available habitat for arthropods to utilize. Knop et al. (2016) documented the broad homogenization that true bugs have experienced in cities, and the loss of host plants may underlie this homogenization. We did find that Enchenopa (tree hoppers) were positively associated with white flower abundance, but this was the only Hemiptera morphospecies associated with floral resources. In addition, a weak negative relationship between morphospecies richness and purple flower abundance was found. These results suggest that specific types of floral resources are required for some arthropod taxa, and that simply increasing overall floral resource availability may not be enough. Additional research is needed to investigate whether targeted plant additions at high impervious sites can counter the negative impacts of impervious surfaces, and how much space is required to make an impact.

Urban greenspaces are often small, and embedded within an urban matrix that promotes generalist arthropod species (Gaublomme et al. 2008). Small urban sites generally do not contain the core habitat needed to maintain diverse arthropods (Christie et al. 2010), and may be more prone to edge effects. Studies have shown that urban greenspace patch size is a correlate of 
299 communities composition for ants (Uno et al. 2010) and natural enemies (Burkman and Gardiner 300 2014). Our results suggest that Hymenoptera also influenced by site structure, as Hymenoptera 301 abundance increased with perimeter-area ratios. Strategies to increase the size and connectivity 302 of urban greenspaces may be important in conserving arthropods, particularly low-mobility 303 arthropod species (Braaker et al. 2014). Sources of new greenspace habitat is available in vacant 304 lots (Gardiner et al. 2013), green roofs (Braaker et al. 2014), or backyard gardens (Pardee and 305 Philpott 2014), amongst others. Increasing the quantity and quality of urban greenspaces not only 306 benefits arthropods, but may enhance the quality of arthropod-mediated ecosystem services like 307 pollination and biological control (Sánchez Domínguez et al. 2020). As cities continue to grow 308 and expand into the surrounding peri-urban environment, city planners should consider leaving 309 patches of non-impervious habitat to maintain diverse arthropod assemblages in cities. Future research should be conducted on the specific ecosystem services provided by

311 individual taxa to better understand how urbanization influences the delivery of these services.

312 There is also a strong need for manipulative studies to investigate whether the mitigation of 313 urban effects (increasing greenspace size, adding shade trees, irrigation) has a positive impact on 314 arthropod communities. Many of the abiotic conditions we documented could also be explained 315 by loss of greenspace habitat, and manipulative studies would provide more precise conclusions. 316 These types of studies would provide critical pieces of information that land managers and urban 317 dwellers could implement on their properties. This study is limited in its ability to provide clear 318 recommendations on the importance of flower species, and future studies to identify floral 319 species in lieu of using floral colors as environmental factors should be necessary. As many 320 arthropods utilized specific host plants, this information would produce a more applicable 321 recommendation to land managers. 


\section{Conclusions}

324

Our results show that both abiotic and biotic conditions are important in the structure of 325 arthropod communities, and plans to conserve arthropods in cities should consider both. The

326

327 328 329 330 331

332 333 334 335 336 337 ecosystem services arthropods provide to humans living within urban environments are valuable. As urban expansion continues, city planners should consider steps to mitigate the impacts of urban heat islands and altered water availability on arthropods and their associated ecosystem services. Increasing the availability of urban greenspaces or repurposing existing urban lots may be important strategies for maintaining diverse arthropod assemblages in urban ecosystems.

\section{Acknowledgements}

We thank the local cities and townships, nonprofit organizations, educational institutions, and faith-based groups for providing access to study sites used for collection. We also thank Cornerstone University for providing us with the facility and resources needed to complete this research. And to Dr. Rob Keys for supplying additional materials and advising throughout the study. In addition, we thank the reviewers and editor of this manuscript for providing valuable feedback that tremendously increased the quality of the manuscript.

\section{References}

Allen, D. C., K. E. McCluney, S. R. Elser, and J. L. Sabo. 2014. Water as a trophic currency in dryland food webs. Frontiers in Ecology and the Environment 12:156-160. 
344 Andrade, R., H. L. Bateman, and Y. Kang. 2017. Seasonality and land cover characteristics drive

345

346

347

348

349

350

351

352

353

354

355

356

357

358

359

360

361

362

363

364

365

366 aphid dynamics in an arid city. Journal of Arid Environments 144:12-20.

Bayley, M., and M. Holmstrup. 1999. Water Vapor Absorption in Arthropods by Accumulation of Myoinositol and Glucose. Science 285:1909-1911.

Bennett, A. B., and C. Gratton. 2012. Local and landscape scale variables impact parasitoid assemblages across an urbanization gradient. Landscape and Urban Planning 104:26-33.

Braaker, S., J. Ghazoul, M. K. Obrist, and M. Moretti. 2014. Habitat connectivity shapes urban arthropod communities: the key role of green roofs. Ecology 95:1010-1021.

Burdine, J. D., and K. E. McCluney. 2019a. Differential sensitivity of bees to urbanizationdriven changes in body temperature and water content. Scientific Reports 9:1643.

Burdine, J. D., and K. E. McCluney. 2019b. Interactive effects of urbanization and local habitat characteristics influence bee communities and flower visitation rates. Oecologia 190:715-723.

Burdine, J., and K. McCluney. 2019c. Interactive effects of urbanization and local habitat characteristics influence bee communities and flower visitation rates. Oecologia 190.

Burkman, C., and M. Gardiner. 2014. Urban greenspace composition and landscape context influence natural enemy community Composition and function. Biological Control.

Cade, B. S. 2015. Model averaging and muddled multimodel inferences. Ecology 96:2370-2382.

Christie, F. J., G. Cassis, and D. F. Hochuli. 2010. Urbanization affects the trophic structure of arboreal arthropod communities. Urban Ecosystems 13:169-180.

Cubino, J. P., J. Cavender-Bares, S. E. Hobbie, S. J. Hall, T. L. E. Trammell, C. Neill, M. L. Avolio, L. E. Darling, and P. M. Groffman. 2019. Contribution of non-native plants to the phylogenetic homogenization of U.S. yard floras. Ecosphere 10:e02638. 
367 Dale, A. G., R. L. Perry, G. C. Cope, and N. Benda. 2020. Floral abundance and richness drive 368 beneficial arthropod conservation and biological control on golf courses. Urban $369 \quad$ Ecosystems 23:55-66.

370 Dar, P. A., and Z. A. Reshi. 2014. Components, processes and consequences of biotic 371 homogenization: A review. Contemporary Problems of Ecology 7:123-136.

372 Diamond, S. E., L. Chick, A. Perez, S. A. Strickler, and R. A. Martin. 2017. Rapid evolution of 373 ant thermal tolerance across an urban-rural temperature cline. Biological Journal of the Linnean Society 121:248-257.

375 Fenoglio, M. S., M. R. Rossetti, and M. Videla. 2020. Negative effects of urbanization on 376 377 terrestrial arthropod communities: A meta-analysis. Global Ecology and Biogeography 29:1412-1429.

378 Gaffin, S. R., C. Rosenzweig, R. Khanbilvardi, L. Parshall, S. Mahani, H. Glickman, R. Goldberg, R. Blake, R. B. Slosberg, and D. Hillel. 2008. Variations in New York city's urban heat island strength over time and space. Theoretical and Applied Climatology

381 94:1-11.

382

Gardiner, M. M., C. E. Burkman, and S. P. Prajzner. 2013. The Value of Urban Vacant Land to Support Arthropod Biodiversity and Ecosystem Services. Environmental Entomology 42:1123-1136.

Gaublomme, E., F. Hendrickx, H. Dhuyvetter, and K. Desender. 2008. The effects of forest patch size and matrix type on changes in carabid beetle assemblages in an urbanized landscape. Biological Conservation 141:2585-2596. 
388 Green, J. M., M. E. Scharf, and G. W. Bennett. 2005. Impacts of Soil Moisture Level on 389 Consumption and Movement of Three Sympatric Subterranean Termites (Isoptera: Rhinotermitidae) in a Laboratory Assay. Journal of Economic Entomology 98:933-937.

391

392

393

394

395

396

397

398

399

400

401

402

403

404

405

406

407

408

409

Groffman, P. M., M. Avolio, J. Cavender-Bares, N. D. Bettez, J. M. Grove, S. J. Hall, S. E. Hobbie, K. L. Larson, S. B. Lerman, D. H. Locke, J. B. Heffernan, J. L. Morse, C. Neill, K. C. Nelson, J. O’Neil-Dunne, D. E. Pataki, C. Polsky, R. R. Chowdhury, and T. L. E. Trammell. 2017. Ecological homogenization of residential macrosystems. Nature Ecology \& Evolution 1:0191.

Groffman, P. M., J. Cavender-Bares, N. D. Bettez, J. M. Grove, S. J. Hall, J. B. Heffernan, S. E. Hobbie, K. L. Larson, J. L. Morse, C. Neill, K. Nelson, J. O’Neil-Dunne, L. Ogden, D. E. Pataki, C. Polsky, R. R. Chowdhury, and M. K. Steele. 2014. Ecological homogenization of urban USA. Frontiers in Ecology and the Environment 12:74-81.

Hall, D. M., G. R. Camilo, R. K. Tonietto, J. Ollerton, K. Ahrné, M. Arduser, J. S. Ascher, K. C. R. Baldock, R. Fowler, G. Frankie, D. Goulson, B. Gunnarsson, M. E. Hanley, J. I. Jackson, G. Langellotto, D. Lowenstein, E. S. Minor, S. M. Philpott, S. G. Potts, M. H. Sirohi, E. M. Spevak, G. N. Stone, and C. G. Threlfall. 2017. The city as a refuge for insect pollinators. Conservation Biology 31:24-29.

Hamblin, A. L., E. Youngsteadt, and S. D. Frank. 2018. Wild bee abundance declines with urban warming, regardless of floral density. Urban Ecosystems 21:419-428.

Hamblin, A. L., E. Youngsteadt, M. M. López-Uribe, and S. D. Frank. 2017. Physiological thermal limits predict differential responses of bees to urban heat-island effects. Biology Letters 13:20170125. 
410 Harrison, X. A., L. Donaldson, M. E. Correa-Cano, J. Evans, D. N. Fisher, C. E. D. Goodwin, B. 411 S. Robinson, D. J. Hodgson, and R. Inger. 2018. A brief introduction to mixed effects 412 modelling and multi-model inference in ecology. PeerJ 6:e4794.

413 Jiang, Y., P. Fu, and Q. Weng. 2015. Assessing the Impacts of Urbanization-Associated Land 414 Use/Cover Change on Land Surface Temperature and Surface Moisture: A Case Study in 415 the Midwestern United States. Remote Sensing 7:4880-4898.

416 Joimel, S., C. Schwartz, N. Maurel, B. Magnus, N. Machon, J. Bel, and J. Cortet. 2019.

417 Contrasting homogenization patterns of plant and collembolan communities in urban $418 \quad$ vegetable gardens. Urban Ecosystems 22:553-566.

419 Khaliq, A., M. Javed, M. Sohail, and M. Sagheer. 2014. Environmental effects on insects and 420 their population dynamics. JOURNAL OF ENTOMOLOGY AND ZOOLOGY

421 STUDIES 2:1-7.

422 Knop, E. 2016. Biotic homogenization of three insect groups due to urbanization. Global Change $423 \quad$ Biology 22:228-236.

424 Lagucki, E., J. D. Burdine, and K. E. McCluney. 2017. Urbanization alters communities of flying 425 arthropods in parks and gardens of a medium-sized city. PeerJ 5:e3620.

426 Lemoine-Rodríguez, R., L. Inostroza, and H. Zepp. 2020. The global homogenization of urban 427 form. An assessment of 194 cities across time. Landscape and Urban Planning 428 204:103949.

429 McCluney, K. E., J. D. Burdine, and S. D. Frank. 2017. Variation in arthropod hydration across $430 \quad$ US cities with distinct climate. Journal of Urban Ecology 3. 
431 McCluney, K. E., T. George, and S. D. Frank. 2018. Water availability influences arthropod

432

433

434

435

436

437

438

439

440

441

442

443

444

445

446

447

448

449

450

451

452

453 water demand, hydration and community composition on urban trees. Journal of Urban Ecology 4.

McCluney, K. E., and J. L. Sabo. 2009. Water availability directly determines per capita consumption at two trophic levels. Ecology 90:1463-1469.

McGlynn, T. P., E. K. Meineke, C. A. Bahlai, E. Li, E. A. Hartop, B. J. Adams, and B. V. Brown. 2019. Temperature accounts for the biodiversity of a hyperdiverse group of insects in urban Los Angeles. Proceedings of the Royal Society B: Biological Sciences 286:20191818.

McIntyre, N. E., J. Rango, W. F. Fagan, and S. H. Faeth. 2001. Ground arthropod community structure in a heterogeneous urban environment. Landscape and Urban Planning 52:257274.

McKinney, M. L. 2004. Measuring floristic homogenization by non-native plants in North America: Floristic homogenization in North America. Global Ecology and Biogeography $13: 47-53$.

McKinney, M. L. 2006. Urbanization as a major cause of biotic homogenization. Biological Conservation 127:247-260.

Merckx, T., and H. V. Dyck. 2019. Urbanization-driven homogenization is more pronounced and happens at wider spatial scales in nocturnal and mobile flying insects. Global Ecology and Biogeography 28:1440-1455.

Miles, L. S., S. T. Breitbart, H. H. Wagner, and M. T. J. Johnson. 2019. Urbanization Shapes the Ecology and Evolution of Plant-Arthropod Herbivore Interactions. Frontiers in Ecology and Evolution 7. 
454 Mody, K., D. Lerch, A.-K. Müller, N. K. Simons, N. Blüthgen, and M. Harnisch. 2020. Flower 455 power in the city: Replacing roadside shrubs by wildflower meadows increases insect 456 numbers and reduces maintenance costs. PLOS ONE 15:e0234327.

457 Otoshi, M. D., P. Bichier, and S. M. Philpott. 2015. Local and Landscape Correlates of Spider 458 Activity Density and Species Richness in Urban Gardens. Environmental Entomology

460

461

462

463

464

465

466

467

468

469

470

471

472

473

474

475

476 44:1043-1051.

Pardee, G. L., and S. M. Philpott. 2014. Native plants are the bee's knees: local and landscape predictors of bee richness and abundance in backyard gardens. Urban Ecosystems $17: 641-659$.

Sánchez Domínguez, M. V., E. González, D. Fabián, A. Salvo, and M. S. Fenoglio. 2020. Arthropod diversity and ecological processes on green roofs in a semi-rural area of Argentina: Similarity to neighbor ground habitats and landscape effects. Landscape and Urban Planning 199:103816.

Sharf, S. 2018. Full List: America’s Fastest-Growing Cities 2018:16.

Shuster, W. D., J. Bonta, H. Thurston, E. Warnemuende, and D. R. Smith. 2005. Impacts of impervious surface on watershed hydrology: A review. Urban Water Journal 2:263-275.

Smidt, S. J., A. Tayyebi, A. D. Kendall, B. C. Pijanowski, and D. W. Hyndman. 2018. Agricultural implications of providing soil-based constraints on urban expansion: Land use forecasts to 2050. Journal of Environmental Management 217:677-689.

Turo, K. J., and M. M. Gardiner. 2019. From potential to practical: conserving bees in urban public green spaces. Frontiers in Ecology and the Environment 17:167-175.

Turrini, T., and E. Knop. 2015. A landscape ecology approach identifies important drivers of urban biodiversity. Global Change Biology 21:1652-1667. 
477 United Nations. 2018. Revision of world urbanized prospects.

478 Uno, S., J. Cotton, and S. M. Philpott. 2010. Diversity, abundance, and species composition of 479 ants in urban green spaces. Urban Ecosystems 13:425-441.

480 Whitehouse, M. 2004. Shochat E., Stefanov, W., Whitehouse M.E.A., Faeth S. 2004

481 Urbanization and spider diversity: influences of human modification of habitat structure 482 and productivity. Ecological Applications 14 (1) 268-280. Ecological Applications $483 \quad 14: 268-280$.

484 Wilson, C. J., and M. A. Jamieson. 2019. The effects of urbanization on bee communities 485 depends on floral resource availability and bee functional traits. PLOS ONE 486 14:e0225852.

487 Wittig, R., and U. Becker. 2010. The spontaneous flora around street trees in cities—A striking 488 example for the worldwide homogenization of the flora of urban habitats. Flora Morphology, Distribution, Functional Ecology of Plants 205:704-709.

490

Youngsteadt, E., A. F. Ernst, R. R. Dunn, and S. D. Frank. 2017. Responses of arthropod 491 populations to warming depend on latitude: evidence from urban heat islands. Global

492 Change Biology 23:1436-1447.

493 


\section{Figure 1}

Map displaying research sites included in this study.

This figure (A) shows the 16 sites chosen for collection in June and July 2020 in Grand Rapids, Michigan (USA). Sites marked with squares are urban gardens, and sites marked with circles are pocket prairies. The background color shows percent impervious surface, with darker colors containing high densities of impervious surfaces. This map was constructed using the 2016 National Landcover Dataset (NLCD) percent developed imperviousness layer (Homer et al. 2020) in ArcGIS, and Google Earth Pro v 7.3.3.7786. The ๔ 2017 Google Imagery was taken on July 30,2017 . For panel B, we show an urban garden with a circle surrounding the site to display the $500 \mathrm{~m}$ buffer used for calculating impervious surface. For panel C, we show a pocket prairie.
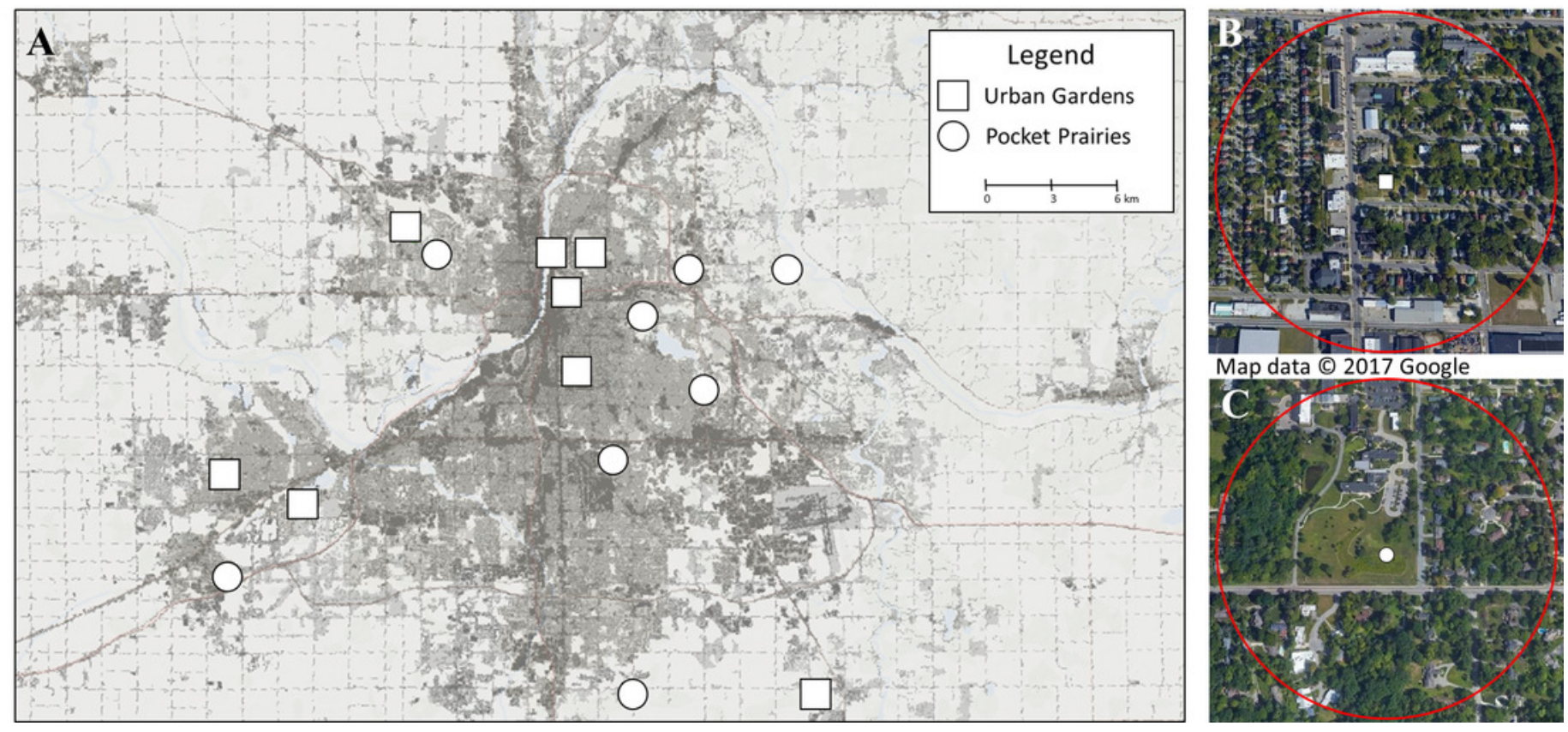
Figure 2

Multidimensional scaling plot showing the relative impact that environmental variables have on arthropod community composition.

Significant environmental variables are shown with bolded text and an arrow. Each circle represents an arthropod morphospecies. The names of specific arthropod morphospecies associated with these variables are listed. We display site type by assigning urban gardens with dotted squares, and pocket prairies with dotted circles.

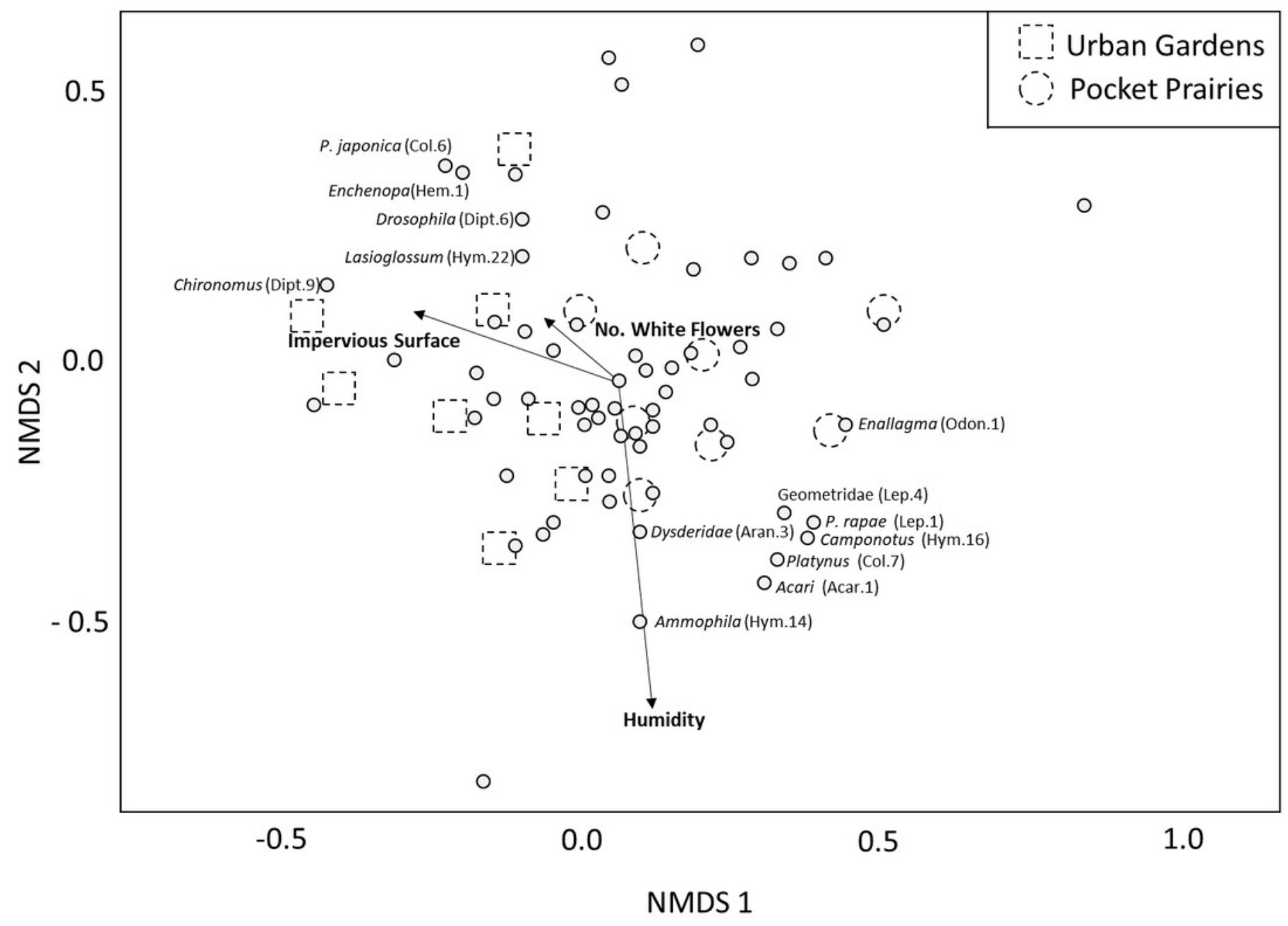


Figure 3

Panel figure displaying significant associations between response and environmental factors.

Data points represent raw data, and regression lines display non-transformed data. Red lines are fitted regressions from $\mathrm{glm}$ models, and dashed black lines represent $95 \%$ confidence intervals. (A) Positive association between total arthropod abundance and humidity $(\mathrm{AICC}=$ 194.94, $R^{2}=0.39$ ). (B) Positive association between Shannon diversity index and humidity $\left(A I C C=-22.23, R^{2}=0.47\right)$.

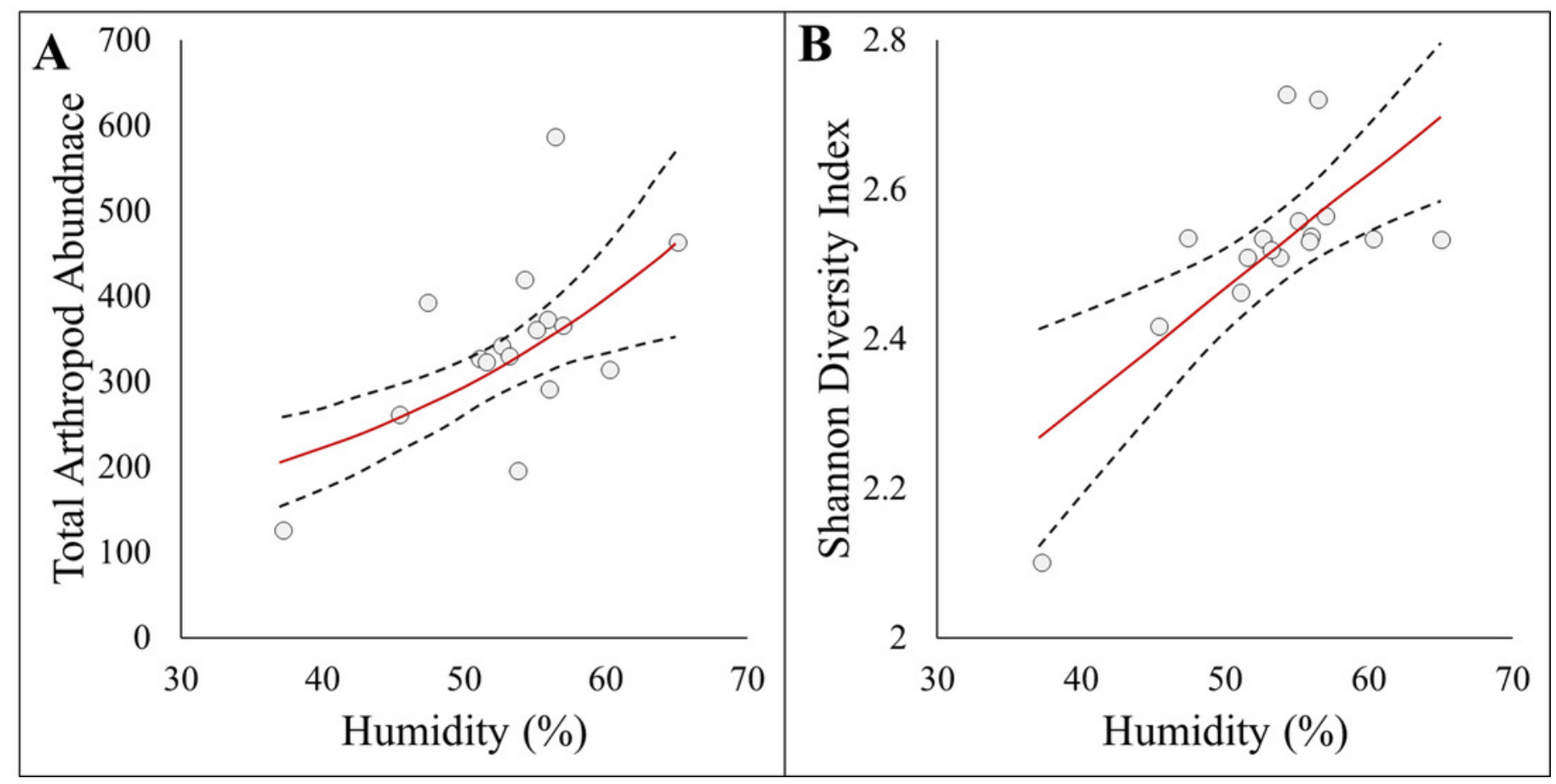




\section{Figure 4}

Panel figure displaying significant associations between the abundances of Hymenoptera and Hemiptera and environmental factors.

Data points represent raw data, and regression lines display non-transformed data. Red lines are fitted regressions from $\mathrm{g} / \mathrm{m}$ models, and dashed black lines represent $95 \%$ confidence intervals. Hemiptera abundance was best explained by an additive model (AICC $=161.21, \mathrm{R}^{2}$ $=0.57$ ) that showed a (A) negative association with impervious surfaces, and (B) positive association with humidity . Hymenoptera abundance showed a (C) negative association with temperature $\left(\mathrm{AICC}=145.32, \mathrm{R}^{2}=0.29\right)$, and $(\mathrm{D})$ positive association with site perimeter-area ratio $\left(\mathrm{AICC}=147.25, \mathrm{R}^{2}=0.20\right)$. 


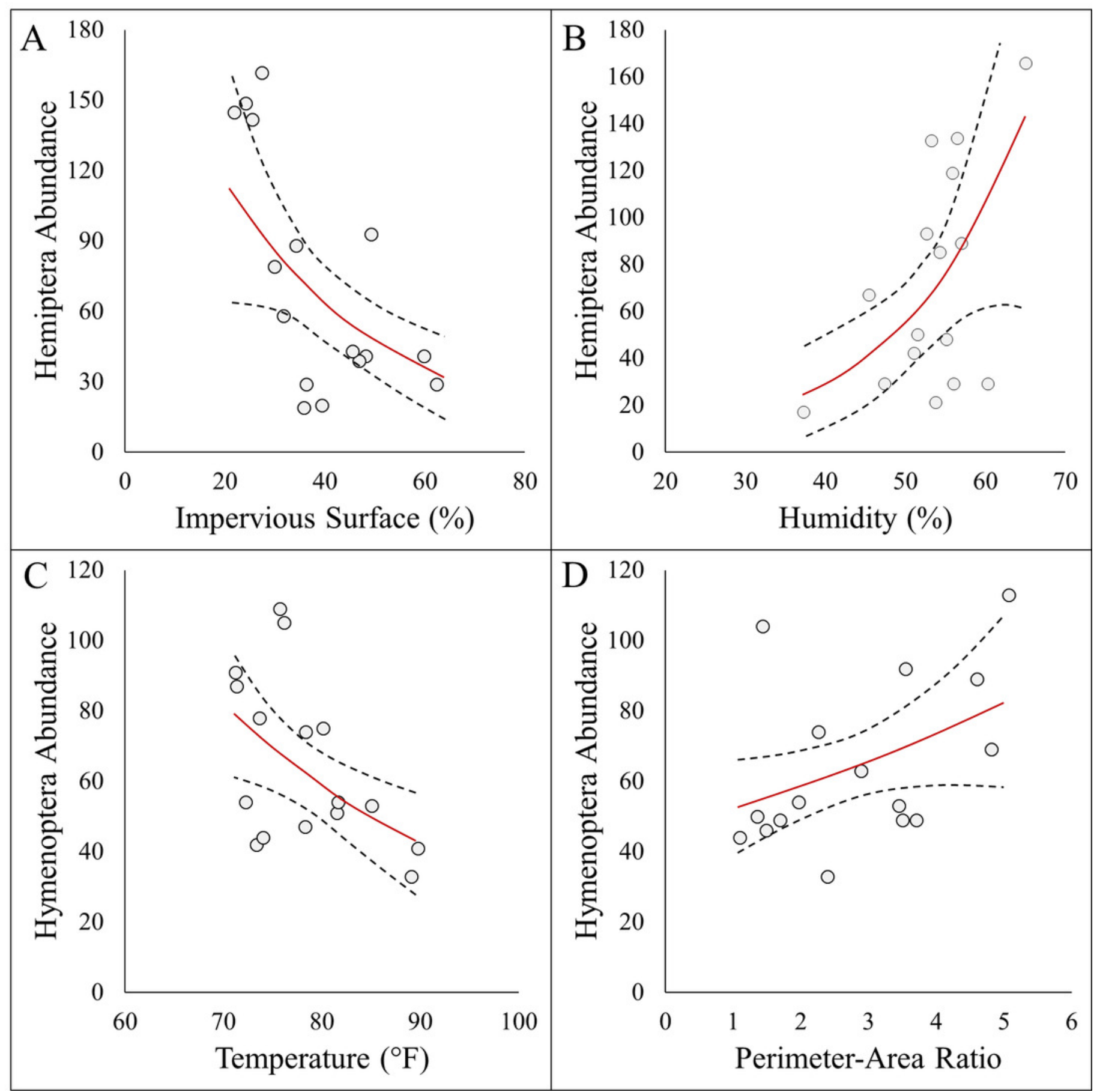




\section{Table $\mathbf{1}$ (on next page)}

Results table from the PERMANOVA analysis comparing arthropod community composition with the seven environmental factors.

An asterisk (*) shows a statistically significant results at $\alpha=0.05$. 


\begin{tabular}{|l|l|l|l|l|l|l|}
\hline Environmental Variable & DF & SS & MS & F-Value & $\mathbf{R}^{\mathbf{2}}$ & P-Value \\
\hline Impervious Surface & 1 & 0.216 & 0.216 & 2.623 & 0.129 & $0.004^{*}$ \\
\hline No. White Flowers & 1 & 0.180 & 0.180 & 2.172 & 0.107 & $0.032^{*}$ \\
\hline No. Purple Flowers & 1 & 0.160 & 0.160 & 1.942 & 0.095 & 0.054 \\
\hline Humidity & 1 & 0.160 & 0.160 & 1.934 & 0.095 & $0.047^{*}$ \\
\hline Site Type & 1 & 0.148 & 0.148 & 1.798 & 0.088 & 0.060 \\
\hline No. Total Flowers & 1 & 0.094 & 0.094 & 1.142 & 0.056 & 0.332 \\
\hline Area-Perimeter Ratio & 1 & 0.077 & 0.077 & 0.937 & 0.046 & 0.513 \\
\hline Temperature & 1 & 0.070 & 0.070 & 0.850 & 0.042 & 0.612 \\
\hline Residuals & 7 & 0.577 & 0.083 & & 0.343 & \\
\hline Total & 15 & 1.683 & & & 1 & \\
\hline
\end{tabular}




\section{Table 2 (on next page)}

Results from generalized-linear models (GLMs) displaying the most parsimonious models.

The null model is also included for reference. For each response metric, we considered models within 2 AICc units to be equivalent. 


\begin{tabular}{|c|c|c|c|c|c|c|c|}
\hline $\begin{array}{l}\text { Response } \\
\text { Metric }\end{array}$ & $\begin{array}{c}\text { Environmental } \\
\text { Variable(s) }\end{array}$ & AICc & $\mathbf{R}^{2}$ & Estimate & SE & $\begin{array}{c}\mathrm{T} / \mathrm{Z} \\
\text { Value }\end{array}$ & $\begin{array}{c}\mathbf{P} \\
\text { Value }\end{array}$ \\
\hline \multirow{2}{*}{ Abundance } & Humidity & 194.04 & 0.39 & 0.036 & 0.010 & 3.543 & $<0.001$ \\
\hline & Null Model & 199.09 & ---- & 5.834 & 0.079 & 73.97 & ---- \\
\hline \multirow{2}{*}{ Diversity } & Humidity & -22.23 & 0.47 & -0.015 & 0.004 & 3.666 & 0.003 \\
\hline & Null Model & -14.54 & ---- & 2.618 & 0.034 & 74.03 & $\begin{array}{ll}--- \\
-\cdots\end{array}$ \\
\hline \multirow{2}{*}{ Richness } & No. Purple Flowers & 96.07 & 0.39 & -0.007 & 0.003 & -2.098 & 0.036 \\
\hline & Null Model & 97.95 & ---- & 3.424 & 0.045 & 75.87 & $\begin{array}{ll}--- \\
\end{array}$ \\
\hline \multirow{5}{*}{$\begin{array}{l}\text { Hymenoptera } \\
\text { Abundance }\end{array}$} & Temperature & 145.32 & 0.29 & -0.034 & 0.013 & -2.646 & 0.008 \\
\hline & Perimeter-Area Ratio & 147.25 & 0.20 & 0.117 & 0.060 & 1.950 & 0.051 \\
\hline & \multirow{2}{*}{$\begin{array}{l}\text { Temperature }+ \\
\text { Perimeter-Area Ratio }\end{array}$} & \multirow{2}{*}{147.32} & \multirow{2}{*}{0.36} & -0.027 & 0.013 & -2.070 & 0.039 \\
\hline & & & & 0.075 & 0.057 & 1.303 & 0.193 \\
\hline & Null Model & 147.84 & ---- & 4.166 & 0.085 & 49.04 & $\begin{array}{ll}--- \\
-\cdots\end{array}$ \\
\hline \multirow{3}{*}{$\begin{array}{l}\text { Hemiptera } \\
\text { Abundance }\end{array}$} & \multirow{2}{*}{$\begin{array}{l}\text { Imperious Surface }+ \\
\text { Humidity }\end{array}$} & \multirow{2}{*}{161.21} & \multirow{2}{*}{0.57} & 0.029 & 0.009 & -3.220 & 0.001 \\
\hline & & & & 0.054 & 0.018 & 3.033 & 0.002 \\
\hline & Null Model & 168.33 & ---- & 4.276 & 0.161 & 26.52 & ---- \\
\hline $\begin{array}{l}\text { Diptera } \\
\text { Abundance }\end{array}$ & Null Model & 184.93 & ---- & 5.092 & 0.110 & 46.30 & ---- \\
\hline $\begin{array}{l}\text { Hymenoptera } \\
\text { Richness }\end{array}$ & Null Model & 75.01 & ---- & 2.404 & 0.075 & 31.98 & ---- \\
\hline $\begin{array}{l}\text { Hemiptera } \\
\text { Richness }\end{array}$ & Null Model & 62.75 & ---- & 1.447 & 0.121 & 11.93 & ---- \\
\hline $\begin{array}{l}\text { Diptera } \\
\text { Richness }\end{array}$ & Null Model & 64.39 & ---- & 1.812 & 0.101 & 17.94 & ---- \\
\hline
\end{tabular}

